\title{
The Rationale for Using Bacteriophage to Treat and Prevent Periprosthetic Joint Infections
}

\author{
Jonas D. Van Belleghem ${ }^{1+}$, Robert Manasherob ${ }^{2 \dagger}$, Ryszard Międzybrodzki ${ }^{3}$, \\ Paweł Rogóż ${ }^{3}$, Andrzej Górski, Gina A. Suh ${ }^{4}$, Paul L. Bollyky ${ }^{1}$ and \\ Derek F. Amanatullah ${ }^{2 *}$
}

'Division of Infectious Diseases and Geographic Medicine, Department of Medicine, Stanford University, Stanford, CA, United States, ${ }^{2}$ Department of Orthopaedic Surgery, Stanford University, Stanford, CA, United States, ${ }^{3}$ Ludwik Hirszfeld Institute of Immunology and Experimental Therapy, Polish Academy of Sciences, Wrocław, Poland, ${ }^{4}$ Mayo Clinic, Rochester, MN, United States

OPEN ACCESS

Edited by:

Karsten Becker,

University Medicine Greifswald,

Germany

Reviewed by:

Sandra Patricia Morales,

Phage Solutions, Sydney, NSW,

Australia

Devendra Dusane

The Ohio State University,

United States

*Correspondence:

Derek F. Amanatullah

dfa@stanford.edu

tThese authors have contributed equally to this work

Specialty section: This article was submitted to Antimicrobials, Resistance and Chemotherapy,

a section of the journal

Frontiers in Microbiology

Received: 03 August 2020 Accepted: 24 November 2020 Published: 21 December 2020

Citation:

Van Belleghem JD,

Manasherob R, Międzybrodzki R,

Rogóż P, Górski A, Suh GA,

Bollyky PL and Amanatullah DF

(2020) The Rationale for Using Bacteriophage to Treat and Prevent

Periprosthetic Joint Infections.

Front. Microbiol. 11:591021.

doi: 10.3389/fmicb.2020.591021
Prosthetic joint infection (PJI) is a devastating complication after a joint replacement. PJI and its treatment have a high monetary cost, morbidity, and mortality. The lack of success treating PJI with conventional antibiotics alone is related to the presence of bacterial biofilm on medical implants. Consequently, surgical removal of the implant and prolonged intravenous antibiotics to eradicate the infection are necessary prior to re-implanting a new prosthetic joint. Growing clinical data shows that bacterial predators, called bacteriophages (phages), could be an alternative treatment strategy or prophylactic approach for PJI. Phages could further be exploited to degrade biofilms, making bacteria more susceptible to antibiotics and enabling potential combinatorial therapies. Emerging research suggests that phages may also directly interact with the innate immune response. Phage therapy may play an important, and currently understudied, role in the clearance of PJl, and has the potential to treat thousands of patients who would either have to undergo revision surgery to attempt to clear an infections, take antibiotics for a prolonged period to try and suppress the re-emerging infection, or potentially risk losing a limb.

Keywords: periprosthetic joint infection, phage (bacteriophage), treatment, biofilm, immune system

\section{INTRODUCTION}

Joint replacement is a life-enhancing procedure for millions of people around the world. Successful joint replacement improves quality of life by relieving pain as well as restoring function and independence (Giori et al., 2018). It is projected that by 2030 there will be approximately 500,000 hip and 3.5 million knee replacements performed annually in the United States alone (Kurtz et al., 2007). The vast majority of patients undergoing joint replacements experience near painfree function, but an unfortunate minority experience pain and ultimately require additional surgery (Mortazavi et al., 2011). The etiologies of joint replacement failure include aseptic failures from loosening at the bone-cement, cement-implant, or bone-implant interfaces, fracture of the bone or implant, wear debris from the articulation, or poor implant position resulting in joint instability (Mulhall et al., 2006). However, septic failure (i.e., periprosthetic joint infection, PJI) is the most feared and often times the most common reason for joint replacement failure (Tande and Patel, 2014). 
Periprosthetic joint infection is the leading cause of failure for knee replacements and the third leading cause for failure in hip replacements, accounting for between 15 and $25 \%$ of all revision surgeries (Kamath et al., 2015). Nearly 11,000 patients are affected by PJI yearly in the United States alone, costing over $\$ 1.6$ billion in 2020 (Kurtz et al., 2012; Kamath et al., 2015). PJI can be categorized in three groups based on the timing of onset. Early PJI is classified when the infection occurs within 3 months after surgery, where delayed PJI occurs between 3 and 24 months after surgery. Late PJI is categorized when the PJI develops 24 months after the surgery occurred. Common signs and symptoms include swelling, redness, and pain localized to the joint, incisional erythema and/or drainage, as well as fever (Berbari et al., 1998; Bongartz et al., 2008; Ravi et al., 2012; Taylor et al., 2012).

During PJI, bacteria bound to an implant survive the administration of antibiotics by forming an antibiotic-tolerant biofilm, an extracellular polymeric substance of DNA, proteins, and polysaccharides (Fauvart et al., 2011; Urish et al., 2016). The subsequent treatment of PJI requires the removal of these biofilm contaminated implants (i.e., one- or two-stage revision surgery) in addition to the administration of antibiotics. The cost associated with each of these revisions is more than $\$ 25,000$ and is associated with a significant morbidity as well as a one year mortality greater than 10\% (Zmistowski et al., 2013; Kamath et al., 2015). Despite being the focus of research efforts for many years, treatment failure of PJI can be high with failure rates up between 20 and 50\% when the implant is retained (Peel et al., 2011; Namba et al., 2013; Pourzal et al., 2016; Song et al., 2018).

Although PJI can occur in any patient, certain risk factors increase the risk of PJI. Obesity (body mass index, BMI > $35 \mathrm{~kg} / \mathrm{m}^{2}$ ) was generally brought forth as a risk factor but in recent years this has been brought into question (Giori et al., 2018). Additional known factors are rheumatoid arthritis, immunosuppression, and malignancy (Berbari et al., 1998; Bongartz et al., 2008; Jämsen et al., 2009; Peel et al., 2011; Ravi et al., 2012; Taylor et al., 2012; Pourzal et al., 2016). Several studies associate PJI with poor glucose control at surgery, whereby diabetes mellitus is used as a surrogate (Malinzak et al., 2009; Cazanave et al., 2013; Namba et al., 2013; Pourzal et al., 2016). Besides disease-associated risk factors, peri-operative risk factors play an important role as well. One study has shown that hinged-knee prostheses are more frequently infected than standard replacements (Poss et al., 1984; Amanatullah et al., 2015). Additionally, postoperative complications associated with an increased risk of PJI include hematoma, superficial surgical site infection, wound drainage, and wound dehiscence (Berbari et al., 1998; Pulido et al., 2008; Aslam et al., 2010; Peel et al., 2011). Wound closure is critical, as open wounds or poorly apposed skin will more rapidly lead to bacterial colonization and subsequent infection.

Despite the existing treatment strategies for PJI such as surgical debridement and use of local and systemic antibiotics or the use of antimicrobial coatings and texturing, the presence of biofilm and the rise of antibiotic resistance limits the effectiveness of current treatment modalities. The use of bacteriophages (a.k.a., phages), viruses that specifically target bacteria, represents an alternative to therapeutic and preventative models. Understanding phage therapy begins with understanding the bacterial pathogens involved in PJI and how phage therapy can augment current treatment or prophylactic protocols.

\section{BACTERIAL PATHOGENESIS OF PJI}

Southwood et al. (1985) showed that most PJIs occurring within the first year are initiated by microorganisms introduced at the time of surgery (Popa and Dagan, 2011). This is often correlated with longer operation times (Peersman et al., 2006). Bacterial contamination occurs through either direct contact or aerosolized contamination of the prosthesis or periprosthetic tissues. Subsequently microorganisms begin colonizing the surface of the implant.

Staphylococcus is the predominant bacteria associated with PJIs and it likely seeds the joint as the implant crosses the skin (Table 1; Barberán, 2006; Laffer et al., 2006; Montanaro et al., 2011). Gram-positive bacteria, including Staphylococcus aureus and coagulase-negative Staphylococcus (CNS) infect between 50 and $60 \%$ of the implants (Tsukayama et al., 1996; Murdoch et al., 2001; Sendi et al., 2011). Other pathogens play an important role in PJI, including Streptococcus species, Enterococcus, and aerobic Gram-negative bacilli (Table 1; Chodos and Johnson, 2009; Lee et al., 2010; Rodríguez et al., 2010). Only a few contaminating microorganisms are needed to establish an infection and even fewer to establish a PJI. In a rabbit model, $10^{4}$ colony forming units (CFU) of $S$. aureus will create an infection, but when an implant is present less than $10^{2}$ CFU will create a PJI (Southwood et al., 1985). CNS are ubiquitous members of the human microbiome found on the skin with the most frequently identified member being S. epidermidis (Tripathi et al., 2020). Although less common, Enterococcal species account for 12$15 \%$ of early-onset PJI often as part of a polymicrobial infection (Bengtson and Knutson, 1991; Berbari et al., 1998; Cobo et al., 2011; Peel et al., 2012b; Tande and Patel, 2014).

At times a causative bacterial pathogen cannot be isolated during PJI. The inability to grow a pathogen in laboratory culture can be attributed to prior antimicrobial treatment, inadequate use of available microbiological methods, or an inability to detect and recognized the pathogen using currently available diagnostic methods (Tande and Patel, 2014). Clearly, identifying a bacterial pathogen is critical when employing phage therapy to treat or prevent PJI. In some cases, isolation of a bacterial pathogen from the intraoperative swab may enable to prepare an active individualized phage formulation.

Another mechanism of establishing a PJI is the contiguous spread of infection from an adjacent site, called hematogenous seeding (Tande and Patel, 2014). Several studies showed that peri-operative infections at a distant site, including urinary and respiratory tract, are associated with an increased risk of PJI (Berbari et al., 1998; Peersman et al., 2001; Pulido et al., 2008). This may be the result of transient bacteremia from the distant infection site during a high-risk time period. Ultimately, however, PJI originating from remote sites of infection are rare (Popa and Dagan, 2011). 
TABLE 1 | Overview of the most common bacterial pathogens isolated form prosthetic joint infections and their available phages for therapeutic purposes.

\begin{tabular}{|c|c|c|c|}
\hline Infectious bacteria & Occurrence & $\begin{array}{l}\text { Number of phages } \\
\text { available (according } \\
\text { to NCBI) }\end{array}$ & Reference of bacterial infections \\
\hline Staphylococcus aureus & ++++ & 145 & $\begin{array}{l}\text { (Berbari et al., 1998, Berbari et al., 2010; Marculescu et al., 2006; Schäfer } \\
\text { et al., 2008; Biring et al., 2009; Lee et al., 2010; Shukla et al., 2010; Kim } \\
\text { et al., 2011; Kusuma et al., 2011; Mahmud et al., 2012; Peel et al., 2012a) }\end{array}$ \\
\hline Coagulase negative Staphylococcus & ++++ & & $\begin{array}{l}\text { (Berbari et al., 1998, Berbari et al., 2010; Marculescu et al., 2006; Schäfer } \\
\text { et al., 2008; Biring et al., 2009; Lee et al., 2010; Shukla et al., 2010; Kim } \\
\text { et al., 2011) }\end{array}$ \\
\hline Streptococcus species & +++ & 55 & $\begin{array}{l}\text { (Berbari et al., 1998, Berbari et al., 2010; Marculescu et al., 2006; Schäfer } \\
\text { et al., 2008; Biring et al., 2009; Lee et al., 2010; Shukla et al., 2010; Kim } \\
\text { et al., 2011; Kusuma et al., 2011; Mahmud et al., 2012; Peel et al., 2012a) }\end{array}$ \\
\hline Enterococcus species & ++ & 40 & $\begin{array}{l}\text { (Schäfer et al., 2008; Lee et al., 2010; Shukla et al., 2010; Kim et al., 2011; } \\
\text { Peel et al., 2012a) }\end{array}$ \\
\hline Pseudomonas aeruginosa & +++ & 212 & $\begin{array}{l}\text { (Berbari et al., 2010; Lee et al., 2010; Shukla et al., 2010; Kusuma et al., } \\
\text { 2011; Mahmud et al., 2012; Peel et al., 2012a) }\end{array}$ \\
\hline Escherichia coli & ++ & 247 & $\begin{array}{l}\text { (Biring et al., 2009; Lee et al., 2010; Kusuma et al., 2011; Mahmud et al., } \\
\text { 2012) }\end{array}$ \\
\hline Acinetobacter baumannii & + & 59 & (Kim et al., 2011) \\
\hline Klebsiella pneumoniae & + & 94 & (Cano et al., 2020) \\
\hline
\end{tabular}

\section{BACTERIAL BIOFILM}

Biofilm is part of the bacterial lifecycle in PJI (Figure 1). Biofilms are composed of an extracellular matrix made from exopolysaccharides, proteins, teichoic acids, lipids, and extracellular DNA (Arciola et al., 2012). Complex communities of bacteria are engulfed in this extracellular matrix. These communities can be mono- or polymicrobial. One of the consequences of biofilm formation during PJI is the formation

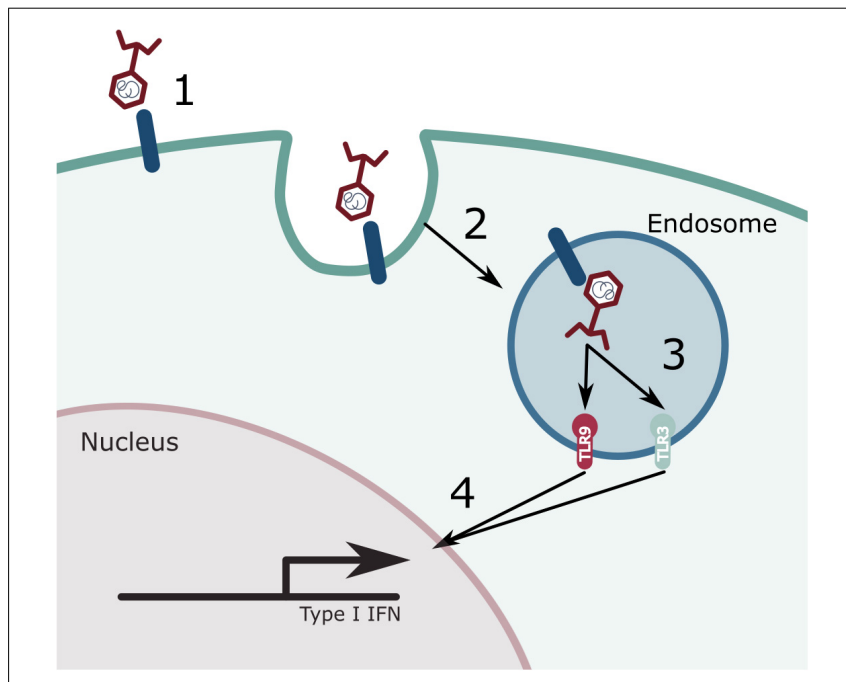

FIGURE 1 | Phage induced immune responses. A variety of immune cells can recognize and interact with phages. (1) Phages are recognized by a currently unknown cell receptor. (2) This leads to the internalization of the phage where it will end up in the endosome. (3) Once present in the endosome, the phage gets degraded and its genetic content can either be recognized by TLR9 (dsDNA) or by TLR3 (dsRNA). (4) The activation of these immune receptors will lead to a signaling cascade and the expression of type I interferon (IFN). of a bacterial reservoir that often leads to symptomatic but non-culturable infection, recurrent or persistent infection, or infectious spread via emboli (i.e., part of the biofilm migrates through the blood) (Azeredo and Sutherland, 2008).

The growth of a biofilm is not static but occurs through multiple stages. Starting with the attachment of the bacterial cell to a surface, followed by the initial growth on the surface, maturation of the biofilm, and finally embolization. In the end, the mature biofilm has a multicellular non-homogeneous structure wherein bacteria communicate with each other through quorum sensing. Quorum sensing make use of chemical signals to help bacteria communicate, coordinate, and cooperate. Quorum is the critical density needed to establish a biofilm colony and express virulence (Miller and Bassler, 2001; Ng and Bassler, 2009). Quorum sensing is a positive feed-forward loop which stimulates population-based gene expression (Seed et al., 1995; Rutherford and Bassler, 2012). Both Gram-negative and Grampositive bacteria utilize these quorum sensing strategies to facilitate intraspecies communication. Additionally, due to the conserved nature of the quorum signal mechanism, inter-species communication also occurs providing a plausible explanation for cooperative polymicrobial biofilms (Mooney et al., 2018).

Bacterial sub-populations have different functions that ultimately support the whole biofilm. In this biofilm state, bacteria are protected from antimicrobials and the immune system (Donlan and Costerton, 2002). This is partially due to the physical separation of the bacteria from the antimicrobials or the immune cells, but also because bacteria are in a metabolic inactive state, called persistence (del Pozo and Patel, 2007; Molina-Manso et al., 2013). This makes the treatment of PJI with conventional antimicrobials very difficult, mandating surgical intervention, including the removal of the prothesis, to achieve a cure. Some antimicrobial agents have an effect against biofilm-resident bacteria such as rifampicin, but ultimately resistance frequently still occurs (Maudsdotter et al., 2019). 
Alternatively, bacteriophages, or their derived proteins can be exploited to treat biofilms.

\section{BACTERIOPHAGE - A BACTERIAL PREDATOR}

Phages, viruses that specifically target and infect bacterial cells, can be exploited to treat biofilms in PJI. Phages consist either of DNA or RNA which is encapsulated in a protein coat called a capsid (van Regenmortel, 1992). Bacteriophages are the most abundant biological entity on the world and occur everywhere in the biosphere. They have colonized even such forbidding habitats as volcanic hot springs. Their main habitats are the oceans and terrestrial topsoil (Ackermann, 2011). Phage particles can be tailed, polyhedral, filamentous, or pleiomorphic (Calendar, 2006; Ackermann, 2009). Tailed phages, representing over $96 \%$ of all known phage species, constitute the order Caudovirales with three families, characterized by contractile (Myoviridae), long and non-contractile (Siphoviridae), or short and non-contractile (Podoviridae) tails (Ackermann, 2011).

The most common phage life cycles are the lytic and lysogenic life cycle. In the lytic life cycle, the phage genome exists within the host but outside the host genome. Lytic or virulent phages repeat a cycle in which self-proliferation is synchronous with the destruction of bacteria (i.e., the lytic cycle or the virulent infection) (Matsuzaki et al., 2005). In this stage, gene expression, genome replication, and morphogenesis occurs (i.e., the formation of the genomes and capsids and the packing of the genomes in the capsids) (Ackermann, 1998). Lysogenic or temperate phages, can remain dormant in the host through integration of its genome in the bacterial genome, called a prophage, replicating along with the host until they are triggered into a lytic lifecycle. For most lysogens this trigger entails DNA damage, which can be triggered by a multitude of stimuli such as antibiotics, reactive oxygen species or UV (Ackermann, 1998; Weinbauer, 2004).

The biological characteristics of phages make them ideal for treating bacterial infections. Their lytic activity, auto-dosing, low inherent toxicity, minimal disruption of normal flora, narrow potential for inducing resistance, lack of cross-resistance with antibiotics, rapid discovery, formulation and application versatility, and biofilm clearance are characteristics looked for in antimicrobials (Loc-Carrillo and Abedon, 2011). Auto-dosing refers to the fact that phages themselves contribute to establishing the bacterial lethal dose by increasing their number during the bacterial-killing process (Carlton, 1999; Skurnik and Strauch, 2006; Chan and Abedon, 2012). A narrow host range limits the number of bacterial types with which selection for specific phage-resistance mechanisms can occur (Hyman and Abedon, 2010). Some phage derived proteins, such as endolysins or depolymerases, are able to degrade the biofilm allowing the phage to destroy the reservoir of bacteria that reside within exopolysaccharide matrix (Hanlon et al., 2001; Tait et al., 2002).

Phages are versatile in terms of formulation and can be combined with antibiotics or incorporated into scaffolds such as hydrogels or wound dressings (Alisky et al., 1998; Kutter et al., 2010; Wroe et al., 2020). They can be applied as liquids, creams, impregnated into solids, in addition to being suitable for most routes of administration (Carlton, 1999; Kutateladze and Adamia, 2010; Kutter et al., 2010). Different phages can be mixed as cocktails to broaden their properties, typically resulting in a collectively greater antibacterial spectrum of activity and lowering the chance of acquiring phage resistant bacterial strains (Merabishvili et al., 2009; Goodridge, 2010).

Phages as pharmaceuticals are protein-based, live-biological agents that can potentially interact with the body's immune system, can actively replicate, and can even evolve during manufacture or use (Loc-Carrillo and Abedon, 2011). Phages possess unique pharmacokinetics and pharmacodynamics that remain poorly understood (Cooper et al., 2016). The pharmacokinetics of phages are complicated due to their self-replicating nature. Critical parameters that affect phage therapy are the phage adsorption rate, burst size (the number of phages released by one infected bacteria), latent period (the time between phage infection and bacterial lysis, i.e., the time needed to assemble new phage progenies), initial phage dose, and density-dependent thresholds (Payne and Jansen, 2001). Another important parameter is the clearance rate of the phage particles from the body fluids by the reticuloendothelial system. Although phages are considered generally well penetrating different tissues and body organs they may significantly differ in bioavailability after oral application (Międzybrodzki et al., 2017b; Dąbrowska, 2019). Their stability in environment is one of the limiting factors for production of standard phage medicinal products which require longer storage (Jault et al., 2018; Jończyk-Matysiak et al., 2019).

\section{PHAGES AND THE IMMUNE SYSTEM}

Historically, phages were regarded as immunologically inert. However, phages do cause a humoral immune response (Ochs et al., 1971; Łusiak-Szelachowska et al., 2014; Hodyra-Stefaniak et al., 2015; Majewska et al., 2015; Zaczek et al., 2016). The production of anti-phage antibodies can affect the outcome of phage therapeutic interventions (Łusiak-Szelachowska et al., 2014). Furthermore, the route of administration plays a big role on the level of antibody production (Zelasko et al., 2016; Łusiak-Szelachowska et al., 2017). For instance, oral administration seems to lead to the lowest level of anti-phage antibodies compared to intraperitoneal injection in mouse models (Dąbrowska, 2019). Moreover, low levels of anti-phage antibodies have also been detected in human subjects after oral administration of phage (Międzybrodzki et al., 2017b). Although an antibody response might be present during or after a phage therapeutic intervention, this does not necessarily lead to a reduction of the therapeutic potential (EusiakSzelachowska et al., 2014, 2017; Zelasko et al., 2016; Dąbrowska, 2018Dą̧browska, 2019).

However, recent research has demonstrated a phage-induced innate immune response (Figure 1). Moreover, mathematical models have predicted their importance in the outcome of a therapeutic intervention (Van Belleghem et al., 2018). As 
expected, this phage induced response appears to mimic an antiviral response (Van Belleghem et al., 2017; Gogokhia et al., 2019; Sweere et al., 2019). The antiviral immune response is driven by a Toll-like receptor (TLR) 9 response to Caudovirales DNA (Gogokhia et al., 2019) whereas it is driven by a TLR3 response to Inoviridae RNA (Sweere et al., 2019). The antiviral immune response may help the phage escape clearance or enable the bacterial host to thrive.

Interestingly, some phages or their preparations may exert anti-inflammatory activity (Van Belleghem et al., 2017, 2018). A significant decrease in $\mathrm{C}$ reactive proteins (CRP) was observed in some patients treated with phages, even in the absence of clearing the bacterial infection (Gorski et al., 2016). Moreover, it has been shown that Escherichia coli phage T4 presents a strong anti-inflammatory effect in mouse models reflecting the autoimmune reaction corresponding to rheumatoid arthritis (Międzybrodzki et al., 2017a). These observations are in accordance with observations in humans, suggesting that phage therapy may modify the immune responses.

\section{PHAGES AIDING SUPPRESSIVE THERAPY}

The minimal inhibitory concentration (MIC) of an antibiotic is determined on cultured bacteria and does not reflect the susceptibility of the bacteria within a biofilm. Killing the bacteria within a biofilm requires a many-fold higher concentration of antibiotic to achieve the minimum biofilm eradication concentration (MBEC) (Ricciardi et al., 2020). Thus, the use of suboptimal antibiotic concentrations could lead to antibiotic resistance in the setting of PJI. Phages are an ideal alternative or adjunct to antibiotics for treating or suppressing PJI (Table 1). Phages have a proven track record for combating, and in some cases eradicating biofilms (Tkhilaishvili et al., 2020). Even though bacteria in a biofilm, such as small colony variants, have a decreased cellular metabolic activity that often makes them resistant to antibiotics. Furthermore, studies have shown synergy between the use of systemic antibiotics and phages to treat biofilm-associated infections, although the precise mechanism is currently not known (Yilmaz et al., 2013; Kamal and Dennis, 2015; Torres-Barceló et al., 2016). On the downside, antagonistic effects between phages and antibiotics have been observed as well. In vitro antagonism between a mixture of two $P$. aeruginosa phages and high doses of tobramycin (Kamal and Dennis, 2015) was observed in which MBEC tobramycin was effective against $P$. aeruginosa biofilms, but its effect diminished when phage was added. This is in line with an observation that phage may sequester antibiotics, thus lowering the active concentration (Tarafder et al., 2020). Hence, when combining antibiotics and phages, strategies may have to be considered for sequential administration.

Furthermore, the occurrence of phage resistance provides an additional hurdle for the use of phage as a therapeutic (Smith and Huggins, 1983; Levin and Bull, 2004). In the therapeutic setting, these phage resistant strains can occur in $17-86 \%$ of treated patients, depending on the pathogen (Międzybrodzki et al., 2012). However, phage resistance often comes at the cost of reduced bacterial virulence and can even be accompanied by re-sensitization to antibiotics (Capparelli et al., 2010; Gu et al., 2012; León and Bastías, 2015; Chan et al., 2016; Oechslin, 2018).

Only a limited amount of pre-clinical studies have evaluated the potential use of phages to treat PJI (Yilmaz et al., 2013; Kaur et al., 2016; Kishor et al., 2016; Ferry et al., 2018a,b; Cano et al., 2020), although attempts to treat PJI-like diseases, such as osteomyelitis, with phage date back to the early 1930s (Albee, 1933). Different administration routes can be deployed, as recently reviewed by Dąbrowska (2019), of which oral administration or injection (intraperitoneal, intramuscular, or subcutaneous) are the most common (Dąbrowska, 2019). The actual dose needed to obtain a therapeutic effect is still debated within the field with reports showing as low as $10^{3} \mathrm{pfu} / \mathrm{ml}$ being sufficient to eradicate a bacterial infection (Soothill, 1994; Marza, 2006), with general consensus saying a minimum of $10^{6} \mathrm{pfu} / \mathrm{ml}$ is needed (Morozova et al., 2018).

Phages have been used to treat PJI in the context of antibiotics (Ferry et al., 2018b). For example, in 2018, a patient with relapsing PJI of the right hip was treated by injecting a cocktail of phages into the joint in addition to systemic antibiotics. Eighteen months after phage therapy, the clinical signs of PJI were absent. This case shows the efficacy of phages in a PJI setting, although surgical intervention was still necessary for this treatment and it is unclear whether this represents suppression prior to phage resistance or eradication. Another recent case with a patient with a right total knee arthroplasty 11 years prior, suffering multiple episodes of PJI despite numerous surgeries and prolonged courses of antibiotics, showed progressive clinical worsening and development of severe allergies to antibiotics, had been offered limb amputation for his persistent right prosthetic knee infection due to Klebsiella pneumoniae complex. As a last resort he was offered intravenous phage therapy (Cano et al., 2020). The patient received 40 doses of a single phage spread over 8 weeks, in combination with minocycline and was able to circumvent further surgery. Furthermore, the authors were not able to identify any phage resistant strains over this eight-week course of phage treatment. This might be due to the lower metabolic activity of the bacteria in the biofilm leading to a lower chance of phage resistance to occur.

\section{PHAGES PREVENTING PJI}

Prophylactic strategies require anticipating a certain bacterial infection in order to provide the necessary agents to combat a not yet existing infection. Nevertheless, additional research is needed to further extend the lifetime of these phages after they undergo the coating or impregnation strategies to provide long lasting protection (Figure 2). It is currently not well described what amount of phage inactivation could be expected or is accepted when mixing phages with bone cement or coating them on prosthetic surfaces. Also getting a clear view of the commensal flora of a patient will become valuable in order to make educated guesses as to which phages to prevent PJI. The main difficulty with using phages in this manner is that they will lose their activity after one round of infection. This enables the removal of 


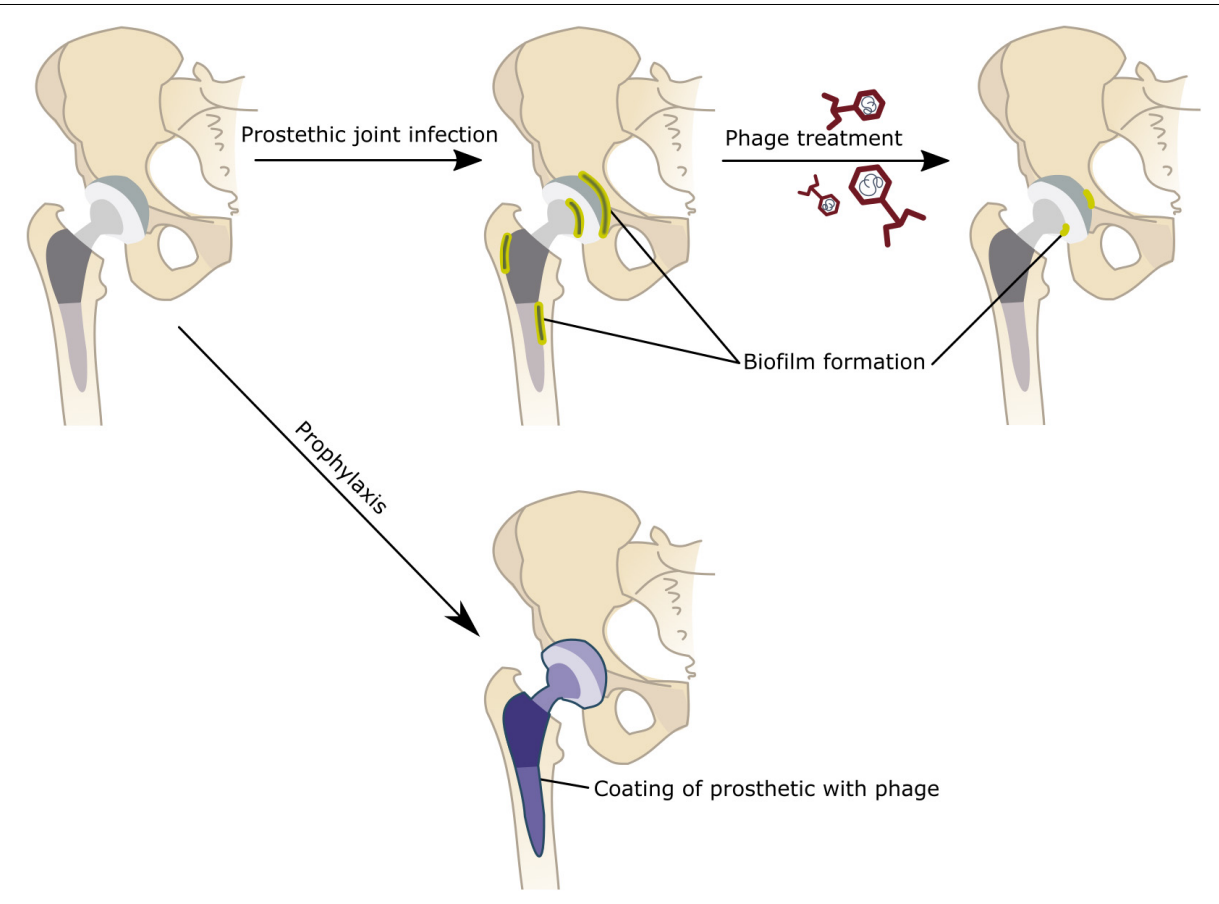

FIGURE 2 | Alternative strategies for treating or preventing Prosthetic joint infections (PJI). Although that joint replacement is a life-enhancing procedure, an unfortunate minority experiences pain and will ultimately require additional surgery. Septic failure, i.e., periprosthetic joint infections, are the most common reason for joint replacement failure. During PJI, bacteria bound to the prosthetic will form biofilm structure that become resistant to antibiotic treatments. Hence the treatment of PJI requires the removal of these biofilm contaminated implants in addition to the administration of antibiotics. The use of phage can form a valid alternative (or additive to classic antibiotic treatments) to treat these PJls without the need of a surgical intervention. These phages can be administered orally as a liquid or in a powdered formulation or injected intravenously or as a hydrogel directly in the joint. Alternatively, phages can be used to prevent the occurrence of PJI by either mixing phages in the bone cement or coating the implant with phages. In case of coating implants with phage, one could opt for a single phage or a cocktail of phages. A gradual release system could be applied, using hydroxypropyl methylcellulose (HPMC) to gradually release and deliver the therapeutic agents at the potential sites of infections. This might prevent the establishment of biofilms and the occurrence of PJls.

an initial infection but would not enable the clearance of a future recurrent infection. To tackle this problem the bioavailability of the phage can be altered by embedding them in a matrix enabling the slow release from the prosthetic bone cement over time and in different waves.

After the selective identification, patients could be decolonized of offending organisms prior to surgery, reducing surgical site infection and PJI after joint arthroplasty. The downside of the use of antibiotics for decolonization, especially in PJI, is the occurrence of antibiotic resistant strains. However, this problem would not arise when phages are used to disinfect the site of surgery. The use of phage would remove the targeted bacteria without disturbing the commensal flora or inducing dysbiosis in the patients gut or skin.

Other approaches that could be used is to directly interfere with the biofilm formation. Research has focused on disrupting biofilm formation by interfering with the quorum sensing (Sully et al., 2014; Atwood et al., 2016; Grandclément et al., 2016). These compounds target a variety of steps in the quorum sensing pathway, including the inhibition of quorum sensing signal production through degradation or substitution of SAM or acylACP (precursors to acyl-homoserine lactone). Sequestration of quorum sensing signals using antibodies have also been evaluated as a potential strategy (Park et al., 2007). Alternative strategies have looked to impair the quorum signal transduction through the disruption kinase domain involved in the quorum sensing transduction (Atwood et al., 2016; Grandclément et al., 2016). Again phages could play a potential role in preventing the formation of biofilms, not due to their direct lytic activity but due to the potential effects of depolymerases present on certain phage tails (Azeredo and Sutherland, 2008; Knecht et al., 2020). These depolymerases could help degrade the biofilm matrix enabling the immune system to more effectively clear a starting bacterial infection.

The optimal form of delivery of phages to the joint implant site is unclear. Phages can be impregnated into bone cement, polymethyl methacrylate (Samokhin et al., 2018). However, once phages are impregnated into polymethyl methacrylate they lose their effective titer between over 1-2 weeks.

Recent research points into the potential of using phages to coat prosthetic materials. Different strategies could be applied, one could coat with a single phage or a phage cocktail either to one specific pathogen or a diverse set of pathogens. Kaur et al. (2016), showed the potential of using phage and antibody coated Kirshner wire to prevent $S$. aureus infection when used at the site of the prosthetic (Kaur et al., 2016). The authors used a hydroxypropyl methylcellulose (HPMC) gel, for the gradual release and delivery of two therapeutic agents at the implant 
site. These coatings of the Kirshner wires remained stable over 20 days, although a 3-log reduction could be observed after initial coating. Moreover, the authors observed that the elution from this gel remained steady for $48 \mathrm{~h}$. A combinatorial approach of the $S$. aureus phage and linezolid led to a reduction of bacterial adhesion by 4-log, as well as reducing the occurrence of phage resistant strains when phage alone was used (Kaur et al., 2016).

\section{CONCLUSION}

Orthopedic devices are prevalent and durable making them one of the most common surgical implant types to become infected (Inzana et al., 2016). All of the materials used for implantable orthopedic devices are easily colonized by bacteria (Gbejuade et al., 2015). Nevertheless, several preventative and therapeutic strategies exist, some more invasive then others. Bacteriophage is a valuable addition as the field looks to control antimicrobial infection in a more effective manner - moving beyond the morbidity of the scalpel and delivering higher doses of resistancegenerating antibiotics. A very promising path is the use of phage coated prosthetics. Although the pitfall here lies in the fact that the immobilized phage will lose its activity after one round of infection. This would still allow to combat an initial infection but not a recurrent one. To tackle this problem the bioavailability of the phage can be altered by embedding them in a matrix enabling the slow release from the prosthetic bone cement over time and in different waves. Alternatively, phage embedded in hydrogels and injected directly at the site of infection could be performed on patients that already have an implant to remove the infection. This would enable to physicians to treat PJIs without the need

\section{REFERENCES}

Ackermann, H.-W. (1998). Tailed bacteriophages: the order caudovirales. $A d v$. Virus Res. 51, 135-201. doi: 10.1016/S0065-3527(08)60785-X

Ackermann, H.-W. (2009). "Phage classification and characterization," in Bacteriophages: Methods and Protocols, Volume 1: Isolation, Characterization, and Interactions, Vol. 501, eds M. R. Clokie and A. M. Kropinski (Totowa, NJ: Humana Press), 127-140. doi: 10.1007/978-1-60327-164-6

Ackermann, H. W. (2011). Bacteriophage taxonomy. Microbiol. Aust. 32, 90-94. doi: 10.1071/MA11090

Albee, F. H. (1933). The treatment of osteomyelitis by bacteriophage. J. Bone Jt. Surg. 15, 58-66.

Alisky, J., Iczkowski, K., Rapoport, A., and Troitsky, N. (1998). Bacteriophages show promise as antimicrobial agents. J. Infect. 36, 5-15. doi: 10.1016/S01634453(98)92874-2

Amanatullah, D. F., Trousdale, R. T., Hanssen, A. D., Lewallen, D. G., and Taunton, M. J. (2015). Non-oncologic total femoral arthroplasty?: retrospective review. J. Arthroplasty 29, 2013-2015. doi: 10.1016/j.arth.2014.05.012

Arciola, C. R., Campoccia, D., Speziale, P., Montanaro, L., and Costerton, J. W. (2012). Biofilm formation in Staphylococcus implant infections. A review of molecular mechanisms and implications for biofilm-resistant materials. Biomaterials 33, 5967-5982. doi: 10.1016/j.biomaterials.2012.05.031

Aslam, S., Reitman, C., and Darouiche, R. O. (2010). Risk factors for subsequent diagnosis of prosthetic joint infection. Infect. Control Hosp. Epidemiol. 31, 298-301. doi: 10.1086/650756

Atwood, D. N., Beenken, K. E., Lantz, T. L., Meeker, D. G., Lynn, W. B., Mills, W. B., et al. (2016). Regulatory mutations impacting antibiotic susceptibility in an established staphylococcus aureus biofilm. Antimicrob. Agents Chemother. 60, 1826-1829. doi: 10.1128/AAC.02750-15 of surgical intervention or removal of the implant, providing layover between the development of phage coated prosthetics and the use of phage in PJI. The use of phages could also enable to combat current unculturable bacteria, on the condition that they can easily be identified through genomic approach. It has been suggested that machine learning approaches can be utilized to either identify, or generate through synthetic genomics, based on the genomic information provided on the bacterial target (Leite et al., 2018; Martorell-Marugán et al., 2019; Baláž et al., 2020; Pirnay, 2020).

Nevertheless, to use phages under these circumstances the field needs to further invest in understanding the bioavailability and biodistribution of phages as well as their immunogenicity in order to generate the best outcome for the patients. Although rigorous clinical trials are currently lacking progress has begun to treat PJI with phage.

\section{AUTHOR CONTRIBUTIONS}

All authors participated in the conception, drafting, and/or editing of the manuscript.

\section{FUNDING}

This work was supported by grants KL2TR003143, R21AI133370, R21AI133240, R01AI12492093, and grants from Stanford SPARK, the Falk Medical Research Trust, the Orthopaedic Research and Education Foundation (OREF), and the Cystic Fibrosis Foundation (CFF).

Azeredo, J., and Sutherland, I. (2008). The use of phages for the removal of infectious biofilms. Curr. Pharm. Biotechnol. 9, 261-266. doi: 10.2174/ 138920108785161604

Baláž, A., Kajsík, M., Budiš, J., Szemeš, T., and Turòa, J. (2020). PHERI-phage host exploration tool. bioRxiv [Preprint]. doi: 10.1101/2020.05.13.093773

Barberán, J. (2006). Management of infections of osteoarticular prosthesis. Clin. Microbiol. Infect. 12, 93-101. doi: 10.1111/j.1469-0691.2006.01400.x

Bengtson, S., and Knutson, K. (1991). The infected knee arthroplasty: a 6year follow-up of 357 cases. Acta Orthop. Scand. 62, 301-311. doi: 10.3109/ 17453679108994458

Berbari, E. F., Hanssen, A. D., Duffy, M. C., Steckelberg, J. M., Ilstrup, D. M., Harmsen, W. S., et al. (1998). Risk factors for prosthetic joint infection: case-control study. Clin. Infect. Dis. 27, 1247-1254. doi: 10.1086/514991

Berbari, E. F., Osmon, D. R., Carr, A., Hanssen, A. D., Baddour, L. M., Greene, D., et al. (2010). Dental procedures as risk factors for prosthetic hip or knee infection: a hospital-based prospective case-control study. Clin. Infect. Dis. 50, 8-16. doi: 10.1086/648676

Biring, G. S., Kostamo, T., Garbuz, D. S., Masri, B. A., and Duncan, C. P. (2009). Two-stage revision arthroplasty of the hip for infection using an interim articulated Prostalac hip spacer: a 10- to 15-year follow-up study. J. Bone Jt. Surg. Ser B 91, 1431-1437. doi: 10.1302/0301-620X.91B11.22026

Bongartz, T., Halligan, C. S., Osmon, D. R., Reinalda, M. S., Bamlet, W. R., Crowson, C. S., et al. (2008). Incidence and risk factors of prosthetic joint infection after total hip or knee replacement in patients with rheumatoid arthritis. Arthritis Rheum. 59, 1713-1720. doi: 10.1002/art.24060

Calendar, R. (2006). The Bacteriophages, Vol. xiii. Oxford: Oxford University Press, 746.

Cano, E. J. C., Caflisch, K. M., Bollyky, P. L., Van Belleghem, J. D., Patel, R., Fackler, J., et al. (2020). Phage therapy for limb-threatening prosthetic knee Klebsiella 
pneumoniae infection: Case report and in vitro characterization of anti-biofilm activity. Clin. Infect. Dis. ciaa705. doi: 10.1093/cid/ciaa705

Capparelli, R., Nocerino, N., Lanzetta, R., Silipo, A., Amoresano, A., Giangrande, C., et al. (2010). Bacteriophage-resistant Staphylococcus aureus mutant confers broad immunity against staphylococcal infection in mice. PLoS One 5:e11720. doi: 10.1371/journal.pone.0011720

Carlton, R. M. (1999). Phage therapy: past history and future prospects. Arch. Immunol. Ther. Exp. (Warsz) 47, 267-274.

Cazanave, C., Greenwood-Quaintance, K. E., Hanssen, A. D., Karau, M. J., Schmidt, S. M., Urena, E. O. G., et al. (2013). Rapid molecular microbiologic diagnosis of prosthetic joint infection. J. Clin. Microbiol. 51, 2280-2287. doi: 10.1128/JCM. 00335- 13

Chan, B. K., and Abedon, S. T. (2012). Phage therapy pharmacology. Phage cocktails. Adv. Appl. Microbiol. 78, 1-23. doi: 10.1016/B978-0-12-394805-2. 00001-4

Chan, B. K., Sistrom, M., Wertz, J. E., Kortright, K. E., Narayan, D., and Turner, P. E. (2016). Phage selection restores antibiotic sensitivity in MDR Pseudomonas aeruginosa. Sci. Rep. 6:26717. doi: 10.1038/srep26717

Chodos, M. D., and Johnson, C. A. (2009). Hematogenous infection of a total knee arthroplasty with Klebsiella pneumoniae in association with occult adenocarcinoma of the cecum. J. Arthroplasty 24, 158.e9-158.e13. doi: 10.1016/ j.arth.2007.12.018

Cobo, J., Miguel, L. G. S., Euba, G., Rodríguez, D., García-Lechuz, J. M., Riera, M., et al. (2011). Early prosthetic joint infection: outcomes with debridement and implant retention followed by antibiotic therapy. Clin. Microbiol. Infect. 17, 1632-1637. doi: 10.1111/j.1469-0691.2010.03333.x

Cooper, C. J., Khan Mirzaei, M., and Nilsson, A. S. (2016). Adapting drug approval pathways for bacteriophage-based therapeutics. Front. Microbiol. 7:1209. doi: 10.3389/fmicb.2016.01209

Dąbrowska, K. (2018). Interaction of bacteriophages with the immune system: induction of bacteriophage-specific antibodies. Methods Mol. Biol. 1693, 139150. doi: 10.1146/annurev.micro.55.1.437

Dąbrowska, K. (2019). Phage therapy: what factors shape phage pharmacokinetics and bioavailability? Systematic and critical review. Med. Res. Rev. 39, 20002025. doi: $10.1002 /$ med.21572

del Pozo, J. L., and Patel, R. (2007). The challenge of treating biofilm-associated bacterial infections. Clin. Pharmacol. Ther. 82, 204-209. doi: 10.1038/sj.clpt. 6100247

Donlan, R. M., and Costerton, J. W. (2002). Biofilms: survival mechanisms of clinically relevant microorganisms. Clin. Microbiol. Rev. 15, 167-193. doi: 10. 1128/CMR.15.2.167-193.2002

Fauvart, M., de Groote, V. N., and Michiels, J. (2011). Role of persister cells in chronic infections: clinical relevance and perspectives on anti-persister therapies. J. Med. Microbiol. 60, 699-709. doi: 10.1099/jmm.0.030932-0

Ferry, T., Boucher, F., Fevre, C., Perpoint, T., Chateau, J., Petitjean, C., et al. (2018a). Innovations for the treatment of a complex bone and joint infection due to XDR Pseudomonas aeruginosa including local application of a selected cocktail of bacteriophages. J. Antimicrob. Chemother. 73, 2901-2903. doi: 10. 1093/jac/dky263

Ferry, T., Leboucher, G., Fevre, C., Herry, Y., Conrad, A., Josse, J., et al. (2018b). Salvage debridement, antibiotics and implant retention ("dair") with local injection of a selected cocktail of bacteriophages: is it an option for an elderly patient with relapsing staphylococcus aureus prosthetic-joint infection? Open Forum Infect. Dis. 5, 1-4. doi: 10.1093/ofid/ofy269

Gbejuade, H. O., Lovering, A. M., and Webb, J. C. (2015). The role of microbial biofilms in prosthetic joint infections: a review. Acta Orthop. 86, 147-158. doi: 10.3109/17453674.2014.966290

Giori, N. J., Amanatullah, D. F., Gupta, S., Bowe, T., and Harris, A. H. S. (2018). Risk reduction compared with access to care?: index eligibility criterion for joint replacement. J. Bone Joint Surg. Am. 100, 539-545. doi: 10.2106/jbjs.17.00120

Gogokhia, L., Buhrke, K., Bell, R., Hoffman, B., Brown, D. G., Hanke-Gogokhia, C., et al. (2019). Expansion of bacteriophages is linked to aggravated intestinal inflammation and colitis. Cell Host Microbe 25, 285-299.e8. doi: 10.1016/j. chom.2019.01.008

Goodridge, L. D. (2010). Designing phage therapeutics. Curr. Pharm. Biotechnol. 11, 15-27. doi: 10.2174/138920110790725348

Gorski, A., Międzybrodzki, R., Weber-Dąbrowska, B., Fortuna, W., Letkiewicz, S., Rogóż, P., et al. (2016). Phage therapy: combating infections with potential for evolving from merely a treatment for complications to targeting diseases. Front. Microbiol. 7:1515. doi: 10.3389/FMICB.2016.01515

Grandclément, C., Tannières, M., Moréra, S., Dessaux, Y., and Faure, D. (2016). Quorum quenching: role in nature and applied developments. FEMS Microbiol. Rev. 40, 86-116. doi: 10.1093/femsre/fuv038

Gu, J., Liu, X., Li, Y., Han, W., Lei, L., Yang, Y., et al. (2012). A method for generation phage cocktail with great therapeutic potential. PLoS One 7:e31698. doi: 10.1371/journal.pone.0031698

Hanlon, G. W., Denyer, S. P., Olliff, C. J., and Ibrahim, L. J. (2001). Reduction in exopolysaccharide viscosity as an aid to bacteriophage penetration through Pseudomonas aeruginosa biofilms. Appl. Environ. Microbiol. 67, 2746-2753. doi: 10.1128/AEM.67.6.2746-2753.2001

Hodyra-Stefaniak, K., Miernikiewicz, P., Drapała, J., Drab, M., Jonczyk-Matysiak, E., Lecion, D., et al. (2015). Mammalian Host-Versus-Phage immune response determines phage fate in vivo. Sci. Rep. 5, 3-8. doi: 10.1038/srep14802

Hyman, P., and Abedon, S. T. (2010). Bacteriophage host range and bacterial resistance. Adv. Appl. Microbiol. 70, 217-248. doi: 10.1016/S0065-2164(10) 70007- 1

Inzana, J. A., Schwarz, E. M., Kates, S. L., and Awad, H. A. (2016). Biomaterials approaches to treating implant-associated osteomyelitis. Biomaterials 81, 5871. doi: $10.1016 /$ j.biomaterials.2015.12.012

Jämsen, E., Huhtala, H., Puolakka, T., and Moilanen, T. (2009). Risk factors for infection after knee arthroplasty. J. Bone Jt Surg. Am. 91, 38-47. doi: 10.2106/ JBJS.G.01686

Jault, P., Leclerc, T., Jennes, S., Pirnay, J. P., Que, Y.-A., Resch, G., et al. (2018). Efficacy and tolerability of a cocktail of bacteriophages to treat burn wounds infected by Pseudomonas aeruginosa (PhagoBurn): a randomised, controlled, double-blind phase 1/2 trial. Lancet Infect. Dis. 19, 35-45. doi: 10.1016/S14733099(18)30482-1

Jończyk-Matysiak, E., Łodej, N., Kula, D., Owczarek, B., Orwat, F., Międzybrodzki, R., et al. (2019). Factors determining phage stability/activity: challenges in practical phage application. Expert Rev. Anti Infect. Ther. 17, 583-606. doi: $10.1080 / 14787210.2019 .1646126$

Kamal, F., and Dennis, J. J. (2015). Burkholderia cepacia complex phage-antibiotic synergy (PAS): Antibiotics stimulate lytic phage activity. Appl. Environ. Microbiol. 81, 1132-1138. doi: 10.1128/AEM.02850-14

Kamath, A. F., Ong, K. L., Lau, E., Chan, V., Vail, T. P., Rubash, H. E., et al. (2015). Quantifying the burden of revision total joint arthroplasty for periprosthetic infection. J. Arthroplasty 30, 1492-1497. doi: 10.1016/j.arth.2015.03.035

Kaur, S., Harjai, K., and Chhibber, S. (2016). In vivo assessment of phage and linezolid based implant coatings for treatment of methicillin resistant S. aureus (MRSA) mediated orthopaedic device related infections. PLoS One 11:e0157626. doi: 10.1371/journal.pone.0157626

Kim, Y. H., Choi, Y., and Kim, J. S. (2011). Treatment based on the type of infected TKA improves infection control. Clin. Orthop. Relat. Res. 469, 977-984. doi: 10.1007/s11999-010-1425-2

Kishor, C., Mishra, R. R., Saraf, S. K., Kumar, M., Srivastav, A. K., and Nath, G. (2016). Phage therapy of staphylococcal chronic osteomyelitis in experimental animal model. Indian J. Med. Res. 143, 87-94. doi: 10.4103/0971-5916.178615

Knecht, L. E., Veljkovic, M., and Fieseler, L. (2020). Diversity and function of phage encoded depolymerases. Front. Microbiol. 10:2949. doi: 10.3389/fmicb. 2019.02949

Kurtz, S., Ong, K., Lau, E., Mowat, F., and Halpern, M. (2007). Projections of primary and revision hip and knee arthroplasty in the United States from 2005 to 2030. J. Bone Jt. Surg. 89, 780-785. doi: 10.2106/JBJS.F.00222

Kurtz, S. M., Lau, E., Watson, H., Schmier, J. K., and Parvizi, J. (2012). Economic burden of periprosthetic joint infection in the united states. J. Arthroplasty 27, 61-65.e1. doi: 10.1016/j.arth.2012.02.022

Kusuma, S. K., Ward, J., Jacofsky, M., Sporer, S. M., and Della Valle, C. J. (2011). What is the role of serological testing between stages of two-stage reconstruction of the infected prosthetic knee? Clin. Orthop. Relat. Res. 469, 1002-1008. doi: 10.1007/s11999-010-1619-7

Kutateladze, M., and Adamia, R. (2010). Bacteriophages as potential new therapeutics to replace or supplement antibiotics. Trends Biotechnol. 28, 591595. doi: 10.1016/j.tibtech.2010.08.001

Kutter, E., De Vos, D., Gvasalia, G., Alavidze, Z., Gogokhia, L., Kuhl, S., et al. (2010). Phage therapy in clinical practice: treatment of human infections. Curr. Pharm. Biotechnol. 11, 69-86. doi: 10.2174/138920110790725401 
Laffer, R. R., Graber, P., Ochsner, P. E., and Zimmerli, W. (2006). Outcome of prosthetic knee-associated infection: evaluation of 40 consecutive episodes at a single centre. Clin. Microbiol. Infect. 12, 433-439. doi: 10.1111/j.1469-0691. 2006.01378.x

Lee, J., Kang, C. I., Lee, J. H., Joung, M., Moon, S., Wi, Y. M., et al. (2010). Risk factors for treatment failure in patients with prosthetic joint infections. J. Hosp. Infect. 75, 273-276. doi: 10.1016/j.jhin.2010.03.012

Leite, D. M. C., Brochet, X., Resch, G., Que, Y. A., Neves, A., and Peña-Reyes, C. (2018). Computational prediction of inter-species relationships through omics data analysis and machine learning. BMC Bioinformatics 19:420. doi: 10.1186/ s12859-018-2388-7

León, M., and Bastías, R. (2015). Virulence reduction in bacteriophage resistant bacteria. Front. Microbiol. 6:343. doi: 10.3389/fmicb.2015.00343

Levin, B. R., and Bull, J. J. (2004). Population and evolutionary dynamics of phage therapy. Nat. Rev. Microbiol. 2, 166-173. doi: 10.1038/nrmicro822

Loc-Carrillo, C., and Abedon, S. T. (2011). Pros and cons of phage therapy. Bacteriophage 1, 111-114. doi: 10.4161/bact.1.2.14590

Łusiak-Szelachowska, M., Żaczek, M., Weber-Dąbrowska, B., Międzybrodzki, R., Kłak, M., Fortuna, W., et al. (2014). Phage neutralization by sera of patients receiving phage therapy. Viral Immunol. 27, 295-304. doi: 10.1089/vim.2013. 0128

Łusiak-Szelachowska, M., Zaczek, M., Weber-Dạbrowska, B., Międzybrodzki, R., Letkiewicz, S., Fortuna, W., et al. (2017). Antiphage activity of sera during phage therapy in relation to its outcome. Future Microbiol. 12, 109-117. doi: 10.2217/fmb-2016-0156

Mahmud, T., Lyons, M. C., Naudie, D. D., MacDonald, S. J., and McCalden, R. W. (2012). Assessing the gold standard: A review of 253 two-stage revisions for infected TKA knee. Clin. Orthop. Relat. Res. 470, 2730-2736. doi: 10.1007/ s11999-012-2358-8

Majewska, J., Beta, W., Lecion, D., Hodyra-Stefaniak, K., Kłopot, A., Kaźmierczak, Z., et al. (2015). Oral application of T4 phage induces weak antibody production in the gut and in the blood. Viruses 7, 4783-4799. doi: 10.3390/v7082845

Malinzak, R. A., Ritter, M. A., Berend, M. E., Meding, J. B., Olberding, E. M., and Davis, K. E. (2009). Morbidly obese, diabetic, younger, and unilateral joint arthroplasty patients have elevated total joint arthroplasty infection rates. J. Arthroplasty 24, 84-88. doi: 10.1016/j.arth.2009.05.016

Marculescu, C. E., Berbari, E. F., Hanssen, A. D., Steckelberg, J. M., Harmsen, S. W., Mandrekar, J. N., et al. (2006). Outcome of prosthetic joint infections treated with debridement and retention of components. Clin. Infect. Dis. 42, 471-478. doi: $10.1086 / 499234$

Martorell-Marugán, J., Tabik, S., Benhammou, Y., del Val, C., Zwir, I., Herrera, F., et al. (2019). "Deep learning in omics data analysis and precision medicine," in Computational Biology, (Brisbane: Codon Publications), 37-53. doi: 10.15586/ computationalbiology.2019.ch3

Marza, J. A. S., Soothill, J. S., Boydell, P., and Collyns, T. A. (2006). Multiplication of therapeutically administered bacteriophages in Pseudomonas aeruginosa infected patients. Burns 32, 644-646. doi: 10.1016/j.burns.2006.02.012

Matsuzaki, S., Rashel, M., Uchiyama, J., Sakurai, S., Ujihara, T., Kuroda, M., et al. (2005). Bacteriophage therapy: a revitalized therapy against bacterial infectious diseases. J. Infect. Chemother. 11, 211-219. doi: 10.1007/s10156-005-0408-9

Maudsdotter, L., Ushijima, Y., and Morikawa, K. (2019). Fitness of spontaneous rifampicin-resistant Staphylococcus aureus isolates in a biofilm environment. Front. Microbiol. 10:988. doi: 10.3389/fmicb.2019.00988

Merabishvili, M., Pirnay, J.-P., Verbeken, G., Chanishvili, N., Tediashvili, M., Lashkhi, N., et al. (2009). Quality-controlled small-scale production of a welldefined bacteriophage cocktail for use in human clinical trials. PLoS One 4:e4944. doi: 10.1371/journal.pone.0004944

Międzybrodzki, R., Borysowski, J., Kłak, M., Jończyk-Matysiak, E., ObmińskaMrukowicz, B., Suszko-Pawłowska, A., et al. (2017a). In vivo studies on the influence of bacteriophage preparations on the autoimmune inflammatory process. Biomed. Res. Int. 2017, 1-9. doi: 10.1155/2017/3612015

Międzybrodzki, R., Borysowski, J., Weber-Dạbrowska, B., Fortuna, W., Letkiewicz, S., Szufnarowski, K., et al. (2012). Clinical aspects of phage therapy. Adv. Virus Res. 83, 73-121. doi: 10.1016/B978-0-12-394438-2.00003-7

Miller, M. B., and Bassler, B. L. (2001). Quorum sensing in bacteria. Annu. Rev. Microbiol. 55, 165-199. doi: 10.1146/annurev.micro.55.1.165

Międzybrodzki, R., Kłak, M., Jonczyk-Matysiak, E., Bubak, B., Wójcik, A., Kaszowska, M., et al. (2017b). Means to facilitate the overcoming of gastric juice barrier by a therapeutic staphylococcal bacteriophage A5/80. Front. Microbiol. 8:467. doi: $10.3389 /$ fmicb.2017.00467

Molina-Manso, D., Del Prado, G., Ortiz-Pérez, A., Manrubia-Cobo, M., GómezBarrena, E., Cordero-Ampuero, J., et al. (2013). In vitro susceptibility to antibiotics of staphylococci in biofilms isolated from orthopaedic infections. Int. J. Antimicrob. Agents 41, 521-523. doi: 10.1016/j.ijantimicag.2013.02.018

Montanaro, L., Testoni, F., Poggi, A., Visai, L., Speziale, P., and Arciola, C. R. (2011). Emerging pathogenetic mechanisms of the implantrelated osteomyelitis by Staphylococcus aureus. Int. J. Artif. Organs. 34, 781-788. doi: 10.5301/ijao. 5000052

Mooney, J. A., Pridgen, E. M., Manasherob, R., Suh, G., Blackwell, H. E., Barron, A. E., et al. (2018). Periprosthetic bacterial biofilm and quorum sensing. J. Orthop. Res. 36, 2331-2339. doi: 10.1002/jor.24019

Morozova, V. V., Vlassov, V. V., and Tikunova, N. V. (2018). Applications of bacteriophages in the treatment of localized infections in humans. Front. Microbiol. 9:1696. doi: 10.3389/fmicb.2018.01696

Mortazavi, S. M. J., Vegari, D., Ho, A., Zmistowski, B., and Parvizi, J. (2011). Two-stage exchange arthroplasty for infected total knee arthroplasty: predictors of failure. Clini. Orthop. Relat. Res. 469, 3049-3054. doi: 10.1007/s11999-0112030-8

Mulhall, K. J., Ghomrawi, H. M., Scully, S., Callaghan, J. J., and Saleh, K. J. (2006). Current etiologies and modes of failure in total knee arthroplasty revision. Clin. Orthop. Relat. Res. 446, 45-50. doi: 10.1097/01.blo.0000214421.21712.62

Murdoch, D. R., Roberts, S. A., Fowler, V. G., Shah, M. A., Taylor, S. L., Morris, A. J., et al. (2001). Infection of orthopedic prostheses after Staphylococcus aureus Bacteremia. Clin. Infect. Dis. 32, 647-649. doi: 10.1086/318704

Namba, R. S., Inacio, M. C. S., and Paxton, E. W. (2013). Risk factors associated with deep surgical site infections after primary total knee arthroplasty. J. Bone Jt. Surg. 95, 775-782. doi: 10.2106/JBJS.L.00211

Ng, W.-L., and Bassler, B. L. (2009). Bacterial quorum-sensing network architectures. Annu. Rev. Genet. 43, 197-222. doi: 10.1146/annurev-genet102108-134304

Ochs, H. D., Davis, S. D., and Wedgwood, R. J. (1971). Immunologic responses to bacteriophage phi-X 174 in immunodeficiency diseases. J. Clin. Invest. 50, 2559-2568. doi: 10.1172/JCI106756

Oechslin, F. (2018). Resistance development to bacteriophages occurring during bacteriophage therapy. Viruses 10:351. doi: 10.3390/v10070351

Park, J., Jagasia, R., Kaufmann, G. F., Mathison, J. C., Ruiz, D. I., Moss, J. A., et al. (2007). Infection control by antibody disruption of bacterial quorum sensing signaling. Chem. Biol. 14, 1119-1127. doi: 10.1016/j.chembiol.2007. 08.013

Payne, R. J., and Jansen, V. A. (2001). Understanding bacteriophage therapy as a density-dependent kinetic process. J. Theor. Biol. 208, 37-48. doi: 10.1006/jtbi. 2000.2198

Peel, T. N., Cheng, A. C., Buising, K. L., and Choong, P. F. M. (2012a). Microbiological aetiology, epidemiology, and clinical profile of prosthetic joint infections: are current antibiotic prophylaxis guidelines effective? Antimicrob. Agents Chemother. 56, 2386-2391. doi: 10.1128/AAC.06246-11

Peel, T. N., Cheng, A. C., Choong, P. F. M., and Buising, K. L. (2012b). Early onset prosthetic hip and knee joint infection: treatment and outcomes in Victoria, Australia. J. Hosp. Infect. 82, 248-253. doi: 10.1016/j.jhin.2012.09.005

Peel, T. N., Dowsey, M. M., Daffy, J. R., Stanley, P. A., Choong, P. F. M., and Buising, K. L. (2011). Risk factors for prosthetic hip and knee infections according to arthroplasty site. J. Hosp. Infect. 79, 129-133. doi: 10.1016/j.jhin. 2011.06.001

Peersman, G., Laskin, R., Davis, J., and Peterson, M. (2001). Infection in total knee replacement. Clin. Orthop. Relat. Res. 392, 15-23. doi: 10.1097/00003086200111000-00003

Peersman, G., Laskin, R., Davis, J., Peterson, M. G. E., and Richart, T. (2006). Prolonged operative time correlates with increased infection rate after total knee arthroplasty. HSS J. 2, 70-72. doi: 10.1007/s11420-005-0130-2

Pirnay, J. (2020). Phage therapy in the year 2035. Front. Microbiol. 11:1171. doi: 10.3389/fmicb.2020.01171

Popa, O., and Dagan, T. (2011). Trends and barriers to lateral gene transfer in prokaryotes. Curr. Opin. Microbiol. 14, 615-623. doi: 10.1016/j.mib.2011. 07.027

Poss, R., Thornhill, T. S., Ewald, F. C., Thomas, W. H., Batte, N. J., and Sledge, C. B. (1984). Factors influencing the incidence and outcome of infection following 
total joint arthroplasty. Clin. Orthop. Relat. Res. 182, 117-126. doi: 10.1097/ 00003086-198401000-00015

Pourzal, R., Knowlton, C. B., Hall, D. J., Laurent, M. P., Urban, R. M., and Wimmer, M. A. (2016). How does wear rate compare in well-functioning total hip and knee replacements? A postmortem polyethylene liner study. Clin. Orthop. Relat. Res. 474, 1867-1875. doi: 10.1007/s11999-016-4749-8

Pulido, L., Ghanem, E., Joshi, A., Purtill, J. J., and Parvizi, J. (2008). Periprosthetic joint infection: the incidence, timing, and predisposing factors. Clin. Orthop. Relat. Res. 466, 1710-1715. doi: 10.1007/s11999-008-0209-4

Ravi, B., Escott, B., Shah, P. S., Jenkinson, R., Chahal, J., Bogoch, E., et al. (2012). A systematic review and meta-analysis comparing complications following total joint arthroplasty for rheumatoid arthritis versus for osteoarthritis. Arthritis Rheum. 64, 3839-3849. doi: 10.1002/art.37690

Ricciardi, B. F., Muthukrishnan, G., Masters, E. A., Kaplan, N., Daiss, J. L., and Schwarz, E. M. (2020). New developments and future challenges in prevention, diagnosis, and treatment of prosthetic joint infection. J. Orthop. Res. 38, 14231435. doi: 10.1002/jor.24595

Rodríguez, D., Pigrau, C., Euba, G., Cobo, J., García-Lechuz, J., Palomino, J., et al. (2010). Acute haematogenous prosthetic joint infection: prospective evaluation of medical and surgical management. Clin. Microbiol. Infect. 16, 1789-1795. doi: 10.1111/j.1469-0691.2010.03157.x

Rutherford, S. T., and Bassler, B. L. (2012). Bacterial quorum sensing: its role in virulence and possibilities for its control. Cold Spring Harb. Perspect. Med. 2:a012427. doi: 10.1101/cshperspect.a012427

Samokhin, A. G., Kozlova, Y. N., Korneev, D. V., Taranov, O. S., Fedorov, E. A., Pavlov, V. V., et al. (2018). Experimental study of the antibacterial activity of the lytic staphylococcus aureus bacteriophage $\mathrm{Ph} 20$ and lytic pseudomonas aeruginosa bacteriophage $\mathrm{Ph} 57$ when modelling impregnation into poly (methylmetacrylate) orthopedic implants (bone cement). Vestn. Ross. Akad. Meditsinskikh Nauk 73, 59-68. doi: 10.15690/vramn905

Schäfer, P., Fink, B., Sandow, D., Margull, A., Berger, I., and Frommelt, L. (2008). Prolonged bacterial culture to identify late periprosthetic joint infection: a promising strategy. Clin. Infect. Dis. 47, 1403-1409. doi: 10.1086/592973

Seed, P. C., Passador, L., and Iglewski, B. H. (1995). Activation of the Pseudomonas aeruginosa lasI gene by LasR and the Pseudomonas autoinducer PAI: an autoinduction regulatory hierarchy. J. Bacteriol. 177, 654-659. doi: 10.1128/jb. 177.3.654-659.1995

Sendi, P., Banderet, F., Graber, P., and Zimmerli, W. (2011). Periprosthetic joint infection following Staphylococcus aureus bacteremia. J. Infect. 63, 17-22. doi: 10.1016/j.jinf.2011.05.005

Shukla, S. K., Ward, J. P., Jacofsky, M. C., Sporer, S. M., Paprosky, W. G., and Della Valle, C. J. (2010). Perioperative testing for persistent sepsis following resection arthroplasty of the hip for periprosthetic infection. J. Arthroplasty 25, 87-91. doi: $10.1016 /$ j.arth.2010.05.006

Skurnik, M., and Strauch, E. (2006). Phage therapy: facts and fiction. Int. J. Med. Microbiol. 296, 5-14. doi: 10.1016/j.ijmm.2005.09.002

Smith, H. W., and Huggins, M. B. (1983). Effectiveness of phages in treating experimental Escherichia coli diarrhoea in calves, piglets and lambs. J. Gen. Microbiol. 129, 2659-2675. doi: 10.1099/00221287-129-8-2659

Song, S. Y., Goodman, S. B., Suh, G., Finlay, A. K., Huddleston, J. I., Maloney, W. J., et al. (2018). Surgery before subspecialty referral for periprosthetic knee infection reduces the likelihood of infection control. Clin. Orthop. Relat. Res. 476, 1995-2002. doi: 10.1097/CORR.0000000000000423

Soothill, J. S. (1994). Bacteriophage prevents destruction of skin grafts by Pseudomonas aeruginosa. Burns 20, 209-211. doi: 10.1016/0305-4179(94) 90184-8

Southwood, R. T., Rice, J. L., McDonald, P. J., Hakendorf, P. H., and Rozenbilds, M. A. (1985). Infection in experimental hip arthroplasties. J. Bone Jt. Surg. Ser B 67, 229-231. doi: 10.1302/0301-620x.67b2.3980532

Sully, E. K., Malachowa, N., Elmore, B. O., Alexander, S. M., Femling, J. K., Gray, B. M., et al. (2014). Selective chemical inhibition of agr quorum sensing in Staphylococcus aureus promotes host defense with minimal impact on resistance. PLoS Pathog. 10:e1004174. doi: 10.1371/journal.ppat.1004174

Sweere, J. M., Van Belleghem, J. D., Ishak, H., Bach, M. S., Popescu, M., Sunkari, V., et al. (2019). Bacteriophage trigger antiviral immunity and prevent clearance of bacterial infection. Science 363:eaat9691. doi: 10.1126/science.aat9691

Tait, K., Skillman, L. C., and Sutherland, I. W. (2002). The efficacy of bacteriophage as a method of biofilm eradication. Biofouling 18, 305-311. doi: 10.1080/ 0892701021000034418
Tande, A. J., and Patel, R. (2014). Prosthetic joint infection. Clin. Microbiol. Rev. 27, 302-345. doi: 10.1128/CMR.00111-13

Tarafder, A. K., von Kügelgen, A., Mellul, A. J., Schulze, U., Aarts, D. G. A. L., and Bharat, T. A. M. (2020). Phage liquid crystalline droplets form occlusive sheaths that encapsulate and protect infectious rod-shaped bacteria. Proc. Natl. Acad. Sci. U.S.A. 117, 4724-4731. doi: 10.1073/pnas.1917726117

Taylor, B. C., Poka, A., French, B. G., Fowler, T. T., and Mehta, S. (2012). Grittistokes amputations in the trauma patient. J. Bone Jt. Surg. Am. 94, 602-608. doi: 10.2106/JBJS.K.00557

Tkhilaishvili, T., Winkler, T., Müller, M., Perka, C., and Trampuz, A. (2020). Bacteriophages as adjuvant to antibiotics for the treatment of periprosthetic joint infection caused by multidrug-resistant Pseudomonas aeruginosa. Antimicrob. Agents Chemother. 64, 1-5. doi: 10.1128/AAC.00924-19

Torres-Barceló, C., Franzon, B., Vasse, M., and Hochberg, M. E. (2016). Long-term effects of single and combined introductions of antibiotics and bacteriophages on populations of Pseudomonas aeruginosa. Evol. Appl. 9, 583-595. doi: 10. 1111/eva.12364

Tripathi, S., Swayampakula, A. K., Deshpande, G. G., Astle, M., Wang, Y., and Welke, K. G. (2020). Illustration of the current practice and outcome comparison of early versus late tracheostomy after pediatric ECMO. Int. J. Artif. Organs. 43, 726-734. doi: 10.1177/0391398820913571

Tsukayama, D. T., Estrada, R., and Gustilo, R. B. (1996). Infection after total hip arthroplasty: a study of the treatment of one hundred and six infections. J. Bone Jt. Surg. Ser A 78, 512-523. doi: 10.2106/00004623-199604000-00005

Urish, K. L., DeMuth, P. W., Kwan, B. W., Craft, D. W., Ma, D., Haider, H., et al. (2016). Antibiotic-tolerant Staphylococcus aureus biofilm persists on arthroplasty materials. Clin. Orthop Relat. Res. 474, 1649-1656. doi: 10.1007/ s11999-016-4720-8

Van Belleghem, J. D., Clement, F., Merabishvili, M., Lavigne, R., and Vaneechoutte, M. (2017). Pro- and anti-inflammatory responses of peripheral blood mononuclear cells induced by Staphylococcus aureus and Pseudomonas aeruginosa phages. Sci. Rep. 7:8004. doi: 10.1038/s41598-01708336-9

Van Belleghem, J. D., Dąbrowska, K., Vaneechoutte, M., Barr, J. J., and Bollyky, P. L. (2018). Interactions between bacteriophage, bacteria, and the mammalian immune system. Viruses 11:10. doi: 10.3390/v11010010

van Regenmortel, M. H. V. (1992). Concept of virus species. Biodivers. Conserv. 1, 263-266. doi: 10.1007/BF00693764

Weinbauer, M. G. (2004). Ecology of prokaryotic viruses. FEMS Microbiol. Rev. 28, 127-181. doi: 10.1016/j.femsre.2003.08.001

Wroe, J. A., Johnson, C. T., and García, A. J. (2020). Bacteriophage delivering hydrogels reduce biofilm formation in vitro and infection in vivo. J. Biomed. Mater. Res. Part A 108, 39-49. doi: 10.1002/jbm.a.36790

Yilmaz, C., Colak, M., Yilmaz, B. C., Ersoz, G., Kutateladze, M., and Gozlugol, M. (2013). Bacteriophage therapy in implant-related infections: an experimental study. J. Bone Jt. Surg. Am. 95, 117-125. doi: 10.2106/JBJS.K. 01135

Zaczek, M., Łusiak-Szelachowska, M., Jończyk-Matysiak, E., Weber-Dabrowska, B., Miedzybrodzki, R., Owczarek, B., et al. (2016). Antibody production in response to Staphylococcal MS-1 phage cocktail in patients undergoing phage therapy. Front. Microbiol. 7:1681. doi: 10.3389/fmicb.2016.01681

Zelasko, S., Górski, A., and Dąbrowska, K. (2016). Delivering phage therapy per os : benefits and barriers. Expert. Rev. Anti Infect. Ther. 15, 167-179. doi: 10.1080/14787210.2017.1265447

Zmistowski, B., Karam, J. A., Durinka, J. B., Casper, D. S., and Parvizi, J. (2013). Periprosthetic joint infection increases the risk of one-year mortality. J. Bone Jt. Surg. Ser A 95, 2177-2184. doi: 10.2106/JBJS.L.00789

Conflict of Interest: The authors declare that the research was conducted in the absence of any commercial or financial relationships that could be construed as a potential conflict of interest.

Copyright (c) 2020 Van Belleghem, Manasherob, Międzybrodzki, Rogóż, Górski, Suh, Bollyky and Amanatullah. This is an open-access article distributed under the terms of the Creative Commons Attribution License (CC BY). The use, distribution or reproduction in other forums is permitted, provided the original author(s) and the copyright owner(s) are credited and that the original publication in this journal is cited, in accordance with accepted academic practice. No use, distribution or reproduction is permitted which does not comply with these terms. 